\title{
Akhlak Guru Terhadap Murid Dalam Proses Pendidikan di Era Milenial Perspektif Imam Ghazali
}

\author{
Muhamad Akip \\ STAI Bumi Silampari Lubuklinggau \\ muhammdaakip@gmail.com
}

\begin{tabular}{ll}
\hline Abstract \\
\hline Article History & This study aims to describe and analyze the \\
Received :16-09-2020 & morals of teachers towards students in the \\
Revised :19-09-2020 & educational process in the millennial era, \\
Accepted:24-09-2020 & the perspective of the ghazali imam in the \\
Keywords: & book Ihya 'Ulumuddin, teachers are a \\
Akhlaq, Teachers and & noble profession so that people who \\
Students & become teachers are emulated by each \\
& student and teachers must have ethics \\
& towards their students (1) Shows the nature \\
& of affection for students. and treat him like \\
& his own son. (2) The teacher must carry out \\
& what has been conveyed to the student. (3) \\
& Teachers are not allowed to ask for favors \\
& or compensation from students (4) Giving \\
& knowledge systematically (5) Teachers are \\
& not allowed to rebuke their students (6) A \\
& teacher is responsible for one of the \\
& subjects. (7) The teacher must explain the \\
& lesson according to the understanding of \\
& the student. (8) Students who are slow in \\
& understanding lessons, should be given \\
clear lessons or (remedial) so that patiently \\
they will receive blessings and ta'zim their \\
teachers. The concept of education put \\
forward by Imam Ghozali is still very \\
relevant to the laws that apply in this \\
millennial era and serves as a bridge \\
between the concept of Imam Ghozali and \\
the Law which in the application process is \\
not in accordance with the concept or law \\
because of the moral position above
\end{tabular}


science and knowledge. the average knowledgeable person can be seen from the morals of both fellow humans and other God's creations.

\section{Pendahuluan}

Pendidikan merupakan upaya yang sistematis secara praktis,sadar dalam meningkatkan sumber daya manusia tersistem dalam pendidikan yang berkualitas. Menyangkut hal tersebut pendidikan yang bertujuan sebagai upaya mengembalikan sumber daya manusia yang berakhlak dan cerdas dilakukan dengan secara menyeluruh. Hal ini bertujuan agar pendidikan mampu berkontribusi lebih terhadap kemajuan kehidupan bangsa dimasa yang akan datang. Namun hal yang terpenting dalam pendidikan itu sendiri adalah hadirnya seorang guru, dimana guru adalah ujung tombak terpenting dalam kemajuan pendidikan dan sebagai masa depan bangsa yang sesuai dengan harapan undang-undang dan ajaran Islam secara kaffa. Para guru umumnya sadra dengan jabatan guru merupakan profesi yang mulia dihadapan manusia dan penciptanya. Guru yang mengabdikan jiwa, raga dan pemikirannya untuk meningkatkan kualitas pendidikan yang bermartabat dimata dunia dan bermanfaat untuk sesama khususnya untuk mereka sendiri, tujuan pendidikan selain memanusiakan sifat manusia itu sendiri pendidikan juga memulikan manusia dihadapan tuhannya dengan beriman, bertakwa, dan berakhlak mulia. Idealnya para guru di tuntut selalu bersikap profesional dan tidak membedakan status ekonomi, pendidikan dan sosial. Tugas utama guru selain mendidik, membimbing, melatih, dan mengembangkan kurikulum, sebagaimana prinsip guru "Ing ngarso song tulodho, seorang guru jika didepan menjadi teladan,, ing madya mangun karso, tut wuri handayani dibelakang memberikan motivasi bagi muridnya (Rushman, 2014 : 15). Pada dunia pendidikan, guru adalah seorang yang menciptakan kondisi dan suasana belajar yang kondusif, yaitu suasana belajar yang menyenangkan, menarik, memberi rasa aman, memberikan ruang pada murid untuuk berfikir aktif, kreatif, dan inovatif dalam mengekpresikan bakat dan minnatnya yang dikolaborasi dengan kemampuan gurunya. Guru merupakan inovator dan penentu proses pendidikan berkualitas. Untuk menjadi seorang guru profesional, mereka wajib memiliki kemampuan Pedagogik, dan social mengaktualisasikan sebagai guru 
profesional (Rushman, $2014: 16$ ).

\section{Metode Penelitian}

Metode yang digunakan dalam tulisan ini bersifat Deskriptif Kualitatif dengan tujuan untuk mendeskripsikan tentang akhlak Guru dan Murid berdasakran pemaham iman Al-Ghazali khususnya pada karya-karyanya. Melalui metode mencatat, menganalisis dan menginterpretasikan data yang berhubungan dengan informasi yang dibutuhkan. Jenis penelitian adalah studi literature merupakan penelitian dengan mengumpulkan data yang diperlukan dari beberapa literature seperti buku-buku, jurnal-jurnal, media cetak dan artikel maupun sumberlainnya dan masih hubungannya dengan akhlak Guru dan Murid berdasakran pemaham iman Al-Ghazali

\section{Pembahasan}

Pengertian Akhlak

Akhlak sangat popular dalam bahasa lisan dan kata akhlak berasal dari bahasa Arab yang sudah diserapkan menjadi kata serapkan. Kata akhlaaq jama"e dari khuluqun yang berarti "perangai, tabiat, adat, kebiasaaan dan sebagainya. (Tim Penyusun Kamus Pusat Pembinaan Bahasa,2005: 19). Menurut pendapat Imam-al-Ghazali sebagai salah satu pakar di bidang akhlak yang dikutip dan Yunahar Ilyas yaitu : Akhlak merupakan sifat yang ada dan telah ditertanam dalam jiwa yang menghasilkan perilaku secara spontan baik atau buruk, tanpa memerlukan pemikiran dan pertimbangan. Jika sifat itu melahirkan perbuatan yang baik menurut akal dan syariat, maka disebut akhlak yang baik, dan bila lahir darinya perbuatan yang buruk, maka disebut akhlak yang buruk (Yunahar Ilyas,2006: 2). Aminuddin mengutip pendapat Ibnu Maskawah yang memaparkan defenisi akhlak adalah keadaan jiwa yang senantiasa mempengaruhi seseorang untuk berperilaku dengan tidak mempertimbangkan dan memikirkan apa yang dilakukannya.( Aminuddin, 2006 : 94). Asnil Aida Ritonga berpendapat Akhlak merupakan keadaan yang menyatu pada jiwa yang akan melahirkan perilaku spontan, tanpa melalui proses pemikiran, pertimbangan bahakan pengamatan dan pendapat dari siapa pun. (Asnil Aidah Ritonga, 2013 : 309). Pendapat di atas 
penulis menyimpulkan bahwa akhlak itu bersifat spontan, tidak dipikiran dan pertimbangan serta dorongan dari orang lain. Akhlak juga dapat dianggap sebagai pondasi keimanan dan menjadi ukuran bagi orang mu'min yang sudah menjalankan proses muslimnya. Akhlak itu bersumber dari hati dan dapat dipengaruhi oleh lingkungan, pendidikan dan keluarga maka, secara umum akhlak bersumber dari dua hal yaitu akhlak baik dan akhlak buruk.

\section{Macam-macam Akhlak}

Menurut Ibnu Qoyyim ada dua jenis akhlak, yaitu Akhlak Dharuri, Akhlak Muhtasabi:

Akhlak dharuri adalah akhlak yang murni, dalam arti akhlak tersebut sudah secara otomatis merupakan pemberian dari Tuhan secara langsung, tanpa memerlukan latihan, kebiasaan dan pendidikan. Akhlak ini hanya dimiliki oleh manusia yang dikendaki Allah.

Akhlak muhtasabi merupakan akhlak atau budi pekerti yang harus diusahakan dengan jalan berlatih dan membiasakannya, untuk berbuat baik serta cara berfikir yang tepat. Tanpa dilatih, dididik dan dibiasakan, akhlak ini tidak akan terwujud. Akhlak ini yang dimiliki oleh sebagian besar manusia (Chabib Thoha, $1996: 84$ )

Kebiasaan berbuat baik harus dibiasakan sejak dini bahkan dalam kandungan, dengan harapan menjadi manusia yang berbudi luhur dan bermanfaat untuk makhluk ciptaan Allah lainnya, berbakti kepada perintah Allah baik yang tersurat maupun yang tersirat. Adapun pembagian akhlak berdasarkan sifatnya dibagi menjadi dua bagian yaitu akhlak mahmudah (Perilaku Terpuji) dan akhlak mazmumah (Periliaku Tercela). Sedangkan pembagian akhlak berdasarkan objeknya dibagi menjadi dua yaitu Akhlak kepada Khalik dan Kepada Makhluk. (Zainuddin, 1999 : 77)

\section{Kedudukan Akhlak}

Kejayaan masyarakat atau bangsa disebabkan akhlak penduduk atau masyarakat yang baik. Jatuhnya harkat dan martabat manusia karena hilangnya akhlak yang baik. Akhlak bukan hanya sekedar sopan santun, tata krama yang bersifat lahiriyah dari seseorang terhadap orang lain, melainkan lebih dari itu maka jika akhlak selalu disandarkan dengan sifat malu. (Rachmat Djatnika, 1996: 11).

Rendahnya akhlak warga negara telah menjadi salah satu keprihatinan bangsa. Keprihatinan dunia pendidikan Islam, seperti 
mempertontonkan aurat atau hilangnya rasa malu terhadap sesama makhluk Allah yang kita kenal dengan era milenial kebudayaan sering dianggap sebagai salah satu penyebab kemerosotan akhlak manusia itu sendiri. Namun hanya mereka yang memisakan kebudayaan dan akhlak dalam kemajuan filsafat, sains, dan teknologi yang berkembang semakin pesat. Adapun kedudukan akhlak diatas ilmu dan pengetahuan karena seseorang dikatakan berilmu terlihat dari akhlaknya baik sesama manusia maupun ciptaan Allah lainnya.

\section{Peran Guru dalam Mencerdaskan Murid}

Pembelajaran adalah proses memanusiakan manusia yang dimentori oleh seseorang yang sering kita sebut dengan istilah guru. Guru bertugas membantu individu amaupun kelompok untuk mencapai kedewasaan secara intelektual, emosional dan spiritual (Muhamad Akip, 2018 : 45). Guru dituntut sebagai pengajar yang bertugas menyampaikan materi pelajaran tertentu dan harus dapat berperan sebagai pendidik yang menteladani dari berbagai aspek sifat dan sikap dan mengarahkan mereka untuk masa depan bahkan setelah kehidupan dunia. Untuk dapat melaksanakan tugasnya dengan baik seorang guru harus memiliki pengetahuan dan pemahaman yang luas tentang proses dunia pendidikan dan selalu belajar. Kemuliaan dan karisma guru merupakan bagian dari kepribadiannya yang sangat urgen sebagai manifestasi profesionalnya. Karena itu, guru harus memiliki kemampuan mengenali dan mengembangkan kebanggaan pribadi ini sebaik mungkin dengan berperan (Nursyamsi, 2014 : 32 41). 1.Guru sebagai model adalah guru sebagai teladan bagi anak khususnya dan masyarakat pada umumnya. 2. Guru Sebagai Pembimbing adalah guru berusaha membimbing anak agar dapat menemukan berbagai potensi yang dimilikinya, Proses yang terjadi di kelas bukanlah pengajaran tapi pembelajaran. 3.Peranan guru sebagai komunikator pembangunan masyarakat. Seorang guru diharapkan dapat berperan aktif dalam pembangunan di segala bidang yang sedang dilakukan. 4. Guru sebagai administrator. Seorang guru tidak hanya sebagai pendidik dan pengajar, tetapi juga sebagai administrator pada bidang pendidikan dan pembelajaran. 5.Guru harus setia terhadap lembaga, saat ini banyak guru enggan untuk ditempatkan di daerah terpencil, 6.Guru sebagai profesi yang menekankan pada kesetiaan pada lembaga, loyal pada negara. Lebih mementingkan kepentingan umum dari kepentingan pribadi. 


\section{Relevansi Akhlak Guru dan Murid di Era Milenial}

Menurut M Faturohman, generasi millenial mempunyai tujuh sifat dan perilaku yang lebih percaya informasi interaktif daripada informasi Valid, millenial lebih memilih ponsel dibanding TV, millenial wajib punya media social, millenial kurang suka membaca secara teksbook, millenial lebih tahu teknologi dibanding orangtua mereka, millenial cenderung tidak loyal namun bekerja efektif, serta millenial mulai banyak melakukan transaksi secara digital dan tidak jarang terjadi penipuan.

Generasi millenial sangat berpengaruh dalam dunia pendidikan khususnya pada masa. Kecenderungan minat belajar menurun sangat drastis, karena millenial khususnya di Indonesia sudah kecanduan internet yang disalah gunakan, bukan semata untuk mencari informasi berkaitan dengan ilmu pengetahuan, dan pembelajaran. Mereka cenderung pragmatis dan instan. Karena itu, perlu disadari bersama bahwa dalam menyikapi masalah ini perlu dilakukan langkah konkrit, supaya tujuan Pendidikan Nasional tetap konsisten dan eksis dengan mengikuti era millennial. (Mursidin, $2011: 48$ )

Syarat seorang guru adalah S1 atau diploma IV. Kompetensi yang harus dimiliki Guru adalah pedagogik, kompetensi kepribadian, kompetensi sosial dan kompetensi professional yang diperoleh melalui pendidikan profesi namun tidak menutup kemungkinan guru belum menguasai keterampilan tersebut(Citra Umbara, 2005 : 9).

Ihya Ulumuddin, merupakan buku fatwa dan karya Imam Ghazali yang paling besar (Bahri, 1991 : 29). Untuk menuliskan susunan Ihya ulumuddin hingga selesai. Beliau sadar, bahwa semua ilmu yang di punyai tanpa dilanjutkan dengan amalan akan bernilai sia-sia, diibaratkan pohon tanpa berbuah bias memberi kesejukan namun tidak dapat melangsungkan hidup belalui buahnya, begitu pula sebaliknya, amalan tanpa dilandasi ilmu agama tidak akan berubah apa-apa (Ghozali, 2011 : XI).

Orang yang dikaruniai ilmu yang banyak dan beramal juga mengajarkannya kepada orang lain dipandang lebih mulia daripada 
malaikat langit dan bumi. Manusia demikian dapat diibaratkan matahari yang menyinari dirinya sendiri dan memberikan sinarnya kepada benda lain akan di tinggikan derajatnya beberapa tingkat oleh Allah SWT. Hal ini di jelaskan di dalam al-Qur'an surah Mujadalah ayat 11

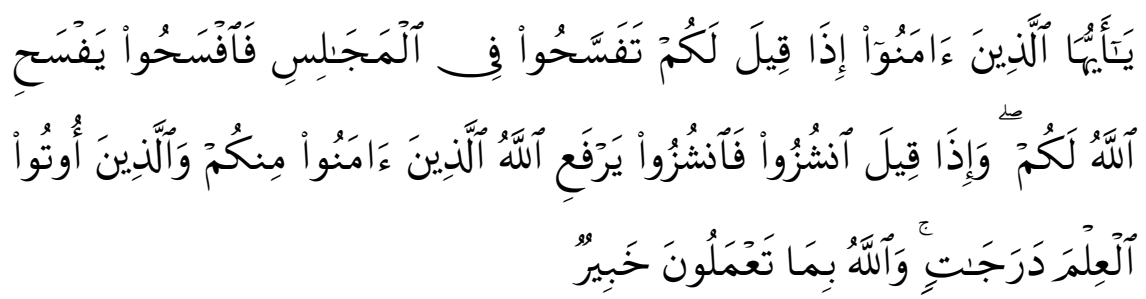

Terjemahan :Hai orang-orang beriman apabila kamu dikatakan kepadamu: "Berlapang-lapanglah dalam majlis", Maka lapangkanlah niscaya Allah akan memberi kelapangan untukmu. dan apabila dikatakan: "Berdirilah kamu", Maka berdirilah, niscaya Allah akan meninggikan orang-orang yang beriman di antaramu dan orang-orang yang diberi ilmu pengetahuan beberapa derajat. dan Allah Maha mengetahui apa yang kamu kerjakan.

Perilaku terbaik dari seorang guru atau orang yang berilmu sebagaimana dikatakan, "siapa yang mempelajari suatu ilmu, kemudian mengamalkannya, dan setelah itu mengajarkannya kepada orang lain, maka derajatnya akan diangkat Allah. Orang berilmu lebih mulia daripada ahli ibadah. Dalam konteks pencapaian tujuan pendidikan karakter, Guru, sebagai sosok yang digugu dan ditiru, mempunyai peran penting dalam aplikasi pendidikan karakter di sekolah maupun di luar sekolah.

Sebagai seorang pendidik harus menjadi figur dalam pandangan anak, guru akan menjadi patokan bagi sikap anak didik. Dalam Undang-Undang Sistem Pendidikan Nasional diamanatkan bahwa seorang guru harus memiliki kompetensi kepribadian yang baik. Guru adalah para pemimpin, orang tua dan juga pendidik. Guru adalah teladan. Guru adalah "digugu" (didengar) dan "ditiru" (dicontoh). Guru bukan sekedar terampil mengajar bagaimana menjawab soal. 
Kompetensi kepribadian tersebut menggambarkan sifat pribadi dari seorang guru. Satu yang penting dimiliki oleh seorang guru dalam rangka pengembangan karakter anak didik adalah guru harus mempunyai kepribadian yang baik dan terintegrasi dan mempunyai mental yang sehat dan profesional yang diharapkan dapat mendorong kemajuan masyarakat, terutama di era milenium ini. Peran guru dalam membimbing moral remaja sehingga dapat menjadi solusi bagi para guru dan untuk mencapai kinerja moral yang baik di era teknologi dan mampu mempertahankan harkat dan martabat keluarga sebagai masyarakat mini yang unggul (Sidiq Sekar Ihsan,2019 : 489).

Konsep pendidikan yang di kemukakan oleh imam Ghozali masih sangat relevan dengan undang-undang yang berlaku pada era milenial ini dan menjadi jembatan antara konsep imam ghozali dan Undang-Undang yang dimana pada proses penerapan tidak sesuai dengan konsep ataupun UU.

\section{Akhlak Guru terhadap Murid Menurut Imam Ghazali}

Guru adalah orang yang sifat dan perbuatannya diguguh dan tiru oleh murid-murinya, Al Ghazali sudah memperingati bahwa ambil hikmah atau perilaku baiknya dalam proses belajar maupun dalam kesehariannya. Imam Al Ghazali juga memiliki etika-etika khusus dan tugas-tugas sebagai berikut : (1) Menunjukan sifat kasih sayang kepada murid. dan memperlakukannya seperti anak sendiri. Maka ia tidak mencari upah atau balasan, mengajar karena Allah. (2) Guru harus melaksanakan apa yang sudah disampaikan kepada Murid. (3) Guru tidak diperkenankan meminta balas budi atau upahan kepada musird sebaliknya guru harus memberi bukan meminta karena akan menurunkan derajat atau karisma seorang guru. (4) Memberi ilmu pengetahuan secara sistematis, ia melarang mempelajari suatu tingkat, sebelum berhak pada tingkat itu. Kemudian menjelakan tujuan menuntut ilmu hanya mendekatkan diri kepada Allah. (5) Guru tidak diperkenankan untuk menghardik muridnya dari berpengarai jahat dengan cara sindiran selama mungkin dan tidak dengan cara terus terang, kasih sayang, dan dengan cara tidak mengejeknnya dan 
ditempat tertentu agar menjadi motivasi. (6) Seorang guru yang bertanggung jawab pada salah satu mata pelajaran, tidak boleh melecehkan mata pelajaran lain didepan muridnya. (7) Guru harus menjelaskan pelajaran menurut pemahaman si murid. Jangan diajarkan pelajaran yang belum sampai pada pemahannya. (8) Pelajar yang labat dalam memahami pelajaran, hendaklah diberikan pelajaran yang jelas atau (remedial) sehingga dengan sabar mereka akan mendapat berkah dan ta'zim gurunya. (Al Ghazali, $2015: 55$ )

\section{Simpulan}

Banyak isitilah tentang Akhlak, Budi pekerti, moral dan etika berasal dari bahasa yunani namun yang paling tepat untuk isitilah dalam pendidikan agama Islam adalah Akhlak yang maknanya untuk arti moral dan etika. Seperti halnya akhlak, secara etimologis etika juga memiliki makna yang sama dengan moral. Guru adalah orang yang memberikan kemanfaatan bagi murid dalam menggapai hakikat penciptaan manusia, yakni kehidupan akhirat. Hal ini sejalan dengan Undang-Undang yang mengatur guru dan dosen pada UU No.14 Tahun 2005 pasal 10 pada kompetensi kepribadian, yang di jelaskan dalam Undang-Undang tersebut salah satunya adalah kompetensi kepribadian sekurang-kurangnya mencakup (a) Guru Harus memiliki rasa kasi saying (b) Guru harus mengikuti teladan Rasul (c) harus menasehati muridnya (d) Guru mencegah murid dari watak dan perilaku jahat (e) Guru tidak merendahkan ilmu lain (f) Guru hendaknya mengetahui batas kemampuan murid (g) Guru hendaknya mengajar sesuatu yang jelas 
Akip, Muhamad. 2018. Ilmu Pendidikan Islam, Yogyakarta : Deepublish

Al Ghazali,2015. Ihya Ulumuddin, Semarang : Toha Putra.

Aminuddin, dkk.2006. Membangun Karakter dan Kepribadian melalui Pendidikan Agama Islam, Jakarta: Graha Ilmu.

Asnil Aidah Ritonga,Irwan,.2013. Tafsir Tarbawi, Bandung : Cita Pustaka Media.

Citra Umbara, Undang-Undang Republik Indonesia Nomor 14 Tahun 2005 Tentang Guru dan Dosen.

Djatnika, Rachmat.1996. Sistem Ethika Islam, Jakarta: Pustaka Panjimas

Ilyas, Yunahar.2006.Kuliah Akhlak, Yogyakarta: Pustaka Pelajar.

Mursidin. 2011.Profesionalisme Guru Menurut al-Qurlan, Hadits dan Ahli Pendidikan, Jakarta:Sedaun.

Nursyamsi. 2014. Pengembangan Kepribadian Guru," Al-Ta lim Journal 21, no. 1

Thoha et al, Chabib. 1996.Metodologi Pengajaran Agama, Yogyakarta: Pustaka Pelajar.

Tim Penyusun Kamus Pusat Pembinaan Bahasa.2005. Kamus Besar Bahasa Indonesi, Jakarta : Balai Pustaka.

Zainuddin, al Islam. 1999. Muamalah dan Akhlak, Bandung: Pustaka Setia. 